SHORT COMMUNICATION

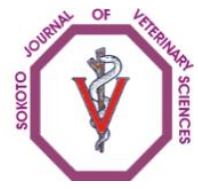

Sokoto Journal of Veterinary Sciences

(P-ISSN 1595-093X/E-ISSN 2315-6201)

Ajibola et al/Sokoto Journal of Veterinary Sciences (2014) 12(2):47-51.

http://dx.doi.org/10.4314/sokjvs.v12i2.8

\title{
Observations on some renal function indices in dogs under ketamine-xylazine anaesthesia
}

\author{
ES Ajibola ${ }^{1}$, SA Rahman ${ }^{1}, \mathrm{KT}$ Biobaku ${ }^{1}, \mathrm{~N} \mathrm{Okwelum}^{2}, \mathrm{JA}$ Oyewusi ${ }^{1}, \mathrm{~B}$ Opeyemi ${ }^{1}$ \& $\mathrm{O}$ \\ Oloruntuga $^{1}$
}

\author{
1. College of Veterinary Medicine, Federal University of Agriculture, Abeokuta. \\ 2. Institute of Food Security, Environmental Resources and Agricultural research Federal University of Agriculture, Abeokuta.
}

\begin{abstract}
*Correspondence: Tel.: 2348052416869, E-mail: esajibola@yahoo.com
Abstract

This study was done to evaluate the effect of an increased dose of ketamine on some renal function indices of Ketamine-Xylazine anaesthetised dogs. Five adult female mongrel dogs assigned to two different treatment groups in a randomized cross over design were used for this study. Each of the dogs received either $10 \mathrm{mg} / \mathrm{kg}$ or $20 \mathrm{mg} / \mathrm{kg}$ ketamine at a week interval. The mean glomerular filtration rate (GFR) of creatinine, absolute and fractional excretion of sodium ( $U N a V, F E_{N a}$ ), urine flow rate (UFR), and plasma sodium clearance were all found to be insignificantly increased in dogs that received the higher dose regime of ketamine. All the dogs in the two treatment groups exhibited levels of glycosuria and hyposthenuria. When plasma sodium concentration of dogs treated with $10 \mathrm{mg} / \mathrm{kg}$ was correlated with $\mathrm{UNaV}$ it was found to be significant and strong $(P<0.05 ; r=0.86)$. It was however strong but insignificant with sodium clearance $(P>0.05 ; r=0.82)$ and creatinine clearance $(P>0.05 ; r=$ 0.39). At $20 \mathrm{mg} / \mathrm{kg}$, the UNaV, sodium clearance and glomerular filtration rate all correlated weakly and insignificantly with plasma sodium concentration. The enhanced diuresis and natriuresis observed in the two treatment groups could be attributed to the effect of xylazine on either the alpha- 2 adrenoceptor of the brain or those on the tubules of the kidney. These effects of xylazine could not be reversed by attempting to competitively antagonize it with a $100 \%$ increase in ketamine dose.
\end{abstract}

Keywords: Diuresis, GFR fractional excretion, Ketamine, Natriuresis, xylazine

Received: 23-08-2013

Accepted: 18-06-2014

\section{Introduction}

Ketamine is a dissociative anaesthetic that causes analgesia by inhibiting the N-Methyl-D-Aspartate receptors in the brain (Hirota \& Lambert, 1996). At a dose rate of $10 \mathrm{mg} / \mathrm{kg}$ in dogs, it causes an increase in heart rate, cardiac output and arterial blood pressure without causing arteriolar vasoconstriction (Haskins et al., 1985). The increase in these haemodynamic variables is attributed to the centrally mediated generalized increase in the sympathetic tone (Wong \& Jenkins, 1974). The cardiovascular effects of ketamine are desirable but balanced anesthesia is achieved when it is combined with sedatives like xylazine. This combination normally provides good analgesia, muscle relaxation and surgical plane anesthesia.

Xylazine is an alpha-2 adrenoceptor agonist which normally inhibits norepinephrine release at presynaptic junctions. The diuretic, natriuretic and kalliuretic effects of ketamine-xylazine anaesthesia have been reported in several animal species. These effects make it unsuitable for use in patients with urinary tract obstruction, dehydration and hypovolemia (Talukder \& Hikasa, 2009). Geriatric dogs are particularly at risk because of their impaired ability to conserve sodium and concentrate urine (Hughes, 2008). 
There is a possibility that ketamine could antagonize the action of xylazine either centrally or peripherally on the distal tubules of the kidneys. This is probably why it substantially reduces urine flow rate and natriuresis when singularly administered to Sprague dawley rats (Cabral et al., 1997).

As a way of understanding the possible mechanism of ketamine action in the kidney, this study will investigate if ketamine, an agent excreted unchanged by the kidney could competitively reverse the action of xylazine when administered at a $100 \%$ dose increase in dogs.

In this present work, comparative clearance studies in dogs receiving two different dosage regimes of ketamine will be used to investigate the action of this drug on some aspect of renal glomerular and tubular functions.

\section{Materials and methods}

This study received the approval of the ethical committee of the College of Veterinary Medicine, Federal University of Agriculture, Abeokuta on the use of animals for experimentation.

Five female adult mongrel dogs that weighed between $4-7 \mathrm{~kg}$ and sourced from Abeokuta local markets were used for the study. The dogs were individually housed in metal cage of $100 \mathrm{~cm}$ by $120 \mathrm{~cm}$ dimension. They were fed on commercial indomie waste once daily and given water adlibitum. All the dogs that were used in this study were clinically healthy and of good hydration status. Each of the dogs went through two different protocols of anesthetic regime in a randomized cross-over design. A wash out period of one week was allowed between each treatment. The dogs were starved of water for six hours prior to the commencement of the experiment.

With animal on lateral recumbency, the cephalic and saphenous veins on the same side were catheterized with Teflon over the needle catheter for fluid administration and blood collection respectively. The urinary bladder was flushed and emptied at the beginning of the experiment via an indwelling urethral catheter of size 7.0 (Foley catheter).

An intravenous bolus administration of $50 \mathrm{mg} / \mathrm{kg}$ of $5 \%$ creatinine in saline followed by a continuous infusion of $0.4 \%$ creatinine at $0.8 \mathrm{mg} / \mathrm{ml} / \mathrm{min}$ at a flow rate of $1.5 \mathrm{ml} / \mathrm{min} / \mathrm{kg}$ for 1 hour was instituted. Xylazine hydrochloride (VMD, Belgium) was first administered to each of the dog at a dose rate of $1 \mathrm{mg} / \mathrm{kg}$ and immediately followed by ketamine hydrochloride (Rotex medica, Germany) at dose of either $10 \mathrm{mg} / \mathrm{kg}$ or $20 \mathrm{mg} / \mathrm{kg}$. Throughout the period of anesthesia the dogs breathed spontaneously.

Thirty minutes was allowed for equilibration with plasma after initiating constant rate infusion of creatinine. A timed urine collection was initiated after this time-out. A paired blood sample was collected at the beginning and end of the 30 minutes urine collection. Urine was collected in a graduated cylinder and blood in Na-EDTA bottles.

The plasma and urine concentrations of sodium, potassium and creatinine were determined spectrophotometrically as described in the Randox test kit manual. The plasma concentrations of sodium, potassium and creatinine were averaged from the values obtained from the paired blood samples of each dog.

The glomerular filtration rate (GFR), sodium clearance $\left(C_{\mathrm{Na}}\right)$, potassium clearance $\left(C_{K}\right)$ absolute sodium excretory rate $\left(\mathrm{U}_{\mathrm{Na}} \mathrm{V}\right)$, absolute potassium excretory rate $\left(U_{K} V\right)$ fractional excretion of sodium $\left(\mathrm{FE}_{\mathrm{Na}}\right)$ and fractional excretion of potassium ( $\left.\mathrm{FE}_{\mathrm{K}}\right)$ were all determined by standard formulae.

All values were expressed as mean $\pm S D$. Mean values of each variable were compared between the two treatment groups using student t-test. Regression analyses were used to assess the relationship between some of the indices studied. $\mathrm{P}<0.05$ was declared significant. All statistical analysis was done using SAS version 9.1.

\section{Results and Discussion}

Table I shows the effects of the two different regimes of anesthesia on electrolyte excretion and clearance indices. The urine flow rate (UFR), absolute urinary sodium excretion $\left(\mathrm{U}_{\mathrm{Na}} \mathrm{V}\right)$ fractional urinary sodium excretion ( $\mathrm{FE}_{\mathrm{Na}}$ ) and absolute urinary creatinine excretion $\left(\mathrm{U}_{\mathrm{Cr}} \mathrm{V}\right)$ were insignificantly higher in the dogs that received $20 \mathrm{mg} / \mathrm{kg}$ ketamine $(P>0.05)$. The glomerular filtration rate (GFR), sodium clearance $\left(\mathrm{C}_{\mathrm{Na}}\right)$ and the plasma sodium concentration of dogs in the two treatment groups were not significantly different $(P>0.05)$.

When plasma sodium concentration of dogs treated with $10 \mathrm{mg} / \mathrm{kg}$ was correlated with $\mathrm{UNaV}$ it was found to be significant and strong ( $P<0.05 ; r=0.86$ ). It was however strong but insignificant with sodium clearance $(P>0.05 ; r=0.82)$ and creatinine clearance ( $P>0.05 ; r=0.39$ ). At $20 \mathrm{mg} / \mathrm{kg}$, the coefficient of correlation( $r$ ) for the relationship between plasma sodium and UNaV, sodium clearance and glomerular filtration rate are $0.18,0.148$ and 0.028 respectively. 
Table I: Urinary electolyte and clearance indices of dogs under two different dosage regime of ketamine

\begin{tabular}{lll}
\hline Urinary electrolyte excretion and clearance indices & $10 \mathrm{mg} / \mathrm{kg}$ Ketamine & $20 \mathrm{mg} / \mathrm{kg}$ Ketamine \\
\hline UFR $(\mathrm{ml} / \mathrm{min})$ & $4.82 \pm 2.42$ & $5.53 \pm 1.71$ \\
$\mathrm{UNaV}(\mathrm{millimoles} / \mathrm{min})$ & $0.85 \pm 0.66$ & $1.04 \pm 0.33$ \\
$\mathrm{UKV}(\mathrm{millimoles} / \mathrm{min})$ & $\mathrm{ND}$ & $0.05 \pm 0.01$ \\
$\mathrm{FE}_{\mathrm{Na}}$ & $0.53 \pm 0.35$ & $0.75 \pm 0.20$ \\
$\mathrm{FE}$ & $\mathrm{ND}$ & $0.95 \pm 0.20$ \\
$\mathrm{GFR}(\mathrm{ml} / \mathrm{min})$ & $2.67 \pm 1.33$ & $2.55 \pm 1.49$ \\
$\mathrm{C}_{\mathrm{Na}}(\mathrm{ml} / \mathrm{min} / \mathrm{kg})$ & $1.49 \pm 0.59$ & $1.62 \pm 0.38$ \\
$\mathrm{C}_{\mathrm{K}}(\mathrm{ml} / \mathrm{min} / \mathrm{kg})$ & $\mathrm{ND}$ & $2.20 \pm 0.40$ \\
$\mathrm{P}_{\mathrm{Na}}(\mathrm{millimoles} / \mathrm{ml})$ & $0.12 \pm 0.005$ & $0.13 \pm 0.006$ \\
$\mathrm{P}_{\mathrm{K}}(\mathrm{millimoles} / \mathrm{L})$ & $\mathrm{ND}$ & $4.22 \pm 0.52$ \\
\hline
\end{tabular}

All values represent mean $\pm S D$. None of the differences between the values were significant. $U_{N a} V, U_{K} V$ are absolute rate of urinary sodium and potassium excretion. $\mathrm{FE}_{\mathrm{Na}}, \mathrm{FE}_{\mathrm{K}}$ are fractional excretion values for sodium and potassium respectively. UFR is the urine flow rate. GFR, $C_{N a}, C_{K}$ represents the glomerular filtration rate, sodium clearance, potassium clearance respectively. $\mathrm{P}_{\mathrm{Na}}$ and $\mathrm{P}_{\mathrm{K}}$ represent plasma sodium and potassium concentrations respectively. ND stands for not determined

We observed in this study that although KetamineXylazine anesthesia induced natriuresis, kalliuresis and diuresis as earlier reported in rats and many other species, the renal handling of water and electrolytes were not different for the two groups of dogs studied. The GFR of the dogs studied were comparable to values obtained in healthy dogs that underwent exogenous creatinine clearance test (Nashat et al., 1976; Watson et al., 2002) Ketamine has been reported to decrease renal blood flow and glomerular filtration rate when used alone in dogs (Hirasawa \&Yanezawa, 1975). This is basically due to its widely reported sympathoexcitatory action.

A tubular rather than a glomerular function defect may be responsible for the natriuresis seen in dogs that received either of the anaesthetic regimes. The fractional excretion of electrolyte, an index of tubular function was abnormally high for both sodium and potassium. Approximately $53 \%$ of the filtered load of sodium and $98 \%$ of potassium compared to the less than $1 \%$ and $20 \%$ respectively considered normal for dogs (DiBartola, 2000), were excreted in the urine of dogs that received $10 \mathrm{mg} / \mathrm{kg}$ Ketamine. At the higher dose level of Ketamine, about $78 \%$ of filtered load of sodium is excreted in urine. Since the excretion of other electrolytes like potassium and calcium is coupled to sodium excretion in the renal tubule, the high load of potassium in the urine is thus expected. The absolute amount of sodium excreted in urine normally reflects the plasma concentration of sodium. Nashat et al. (1976) found impaired tubular reabsorption of sodium responsible for the increased
$\mathrm{U}_{\mathrm{Na}} \mathrm{V}$ seen in dogs with increased plasma sodium concentration. At the lower dose regime of ketamine, we similarly observed that the plasma sodium strongly influenced both the $\mathrm{U}_{\mathrm{Na}} \mathrm{V}$ and sodium clearance. We are also of the opinion that ineffective tubular handling of sodium could account for the considerably high level of sodium excreted in urine of dogs in group one. The abnormally high values of both sodium clearance and $U_{\mathrm{Na}} \mathrm{V}$ and their weak correlations with $\mathrm{P}_{\mathrm{Na}}$ in dogs anaesthetized with $20 \mathrm{mg} / \mathrm{kg}$ of ketamine may be due to the complicating influence of other factors. Beside plasma sodium, other factors like, changes in plasma protein and blood pressure have been reported to influence the amount of sodium excreted in urine (Green \& Farah, 1949; Selkurt \& Post, 1950).

Since the glomerular function of the dogs in this study is normal, the inability of the tubules to reabsorb the filtered water may be partly responsible for the increase UFR which is comparably higher than values obtained from normal unanaesthetised dogs similarly infused with normal saline (Chiu et al., 1976).

Several theories have been advanced to explain the diuresis and natriuresis at the renal tubules during ketamine-xylazine anesthesia. Xylazine and other alpha-2 adrenoceptor agonists have been reported to cause enhanced urine flow rate and increase urinary sodium excretion in animals and man by influencing both arginine vasopressin (AVP) release and the renin angiotensin system (Smyth et al., 1987; Blandford \&Smyth, 1988). These actions are often mediated centrally in the brain and 
peripherally in the renal tubules of the kidney (Cabral et al., 1998; Edwards \& Gellai, 1988). At the central level, stimulation of the alpha-2 adrenoceptor by agonist like xylazine are known to cause renal sympathoinhibition and hence reduced activity of the renin angiotensin activity leading to reduced tubular reabsorption of water and electrolytes (DiBona \& Kopp, 1997; Cabral et al., 1998). Agonists of alpha-2 adrenoceptors are also known to act centrally to inhibit the release of AVP in the paraventricular nuclei of the dog and the pituitary gland of rats (Menegaz et al., 2000; Humphreys et al., 1975). Acting upon the intra renal alpha-2 adrenoceptors, AVP could blunt cyclic adenosine monophosphate (CAMP) release at the cellular level and thus cause a decreased synthesis of aquaporins which are needed for water absorption at the tubules (Gellai \& Edwards, 1988). Within the kidney also, xylazine could enhance tubular excretion of sodium and water by preventing norepinephrine release at presynaptic alpha2adrenoceptors. This action of xylazine indirectly blunts the activity of the post synaptic alpha-1

\section{References}

Blandford DE \& Smyth DD (1988). Renal alpha-2 adrenoceptor blockade decrease sodium and water excretion in anaesthetized rat .European Journal of Pharmacology, 154(2): 117-124.

Cabral AM, Varner KJ \& Kapusta DR (1997). Renal excretory responses produced by central administration of opioid agonists in ketamine and xylazine anaesthetized rats. Journal of Pharmacology and Experimental Therapeutics, 282(2): 609 -616.

Cabral AM, Kapusta DR, Keings VA \& Varner KJ (1998). Central alpha-2 receptor mechanisms contribute enhanced renal responses during ketamine- xylazine anesthesia. American Journal of Physiology, 275(6 Pt 2): R1867-R1874.

Chiu PJ, Brown A, Miller G \& Long J (1976). Renal extraction of gentamicin in anesthetized dogs. Antimicrobial Agents and Chemotherapy, 10 (2): 277 - 282.

DiBartola SP (2000). Clinical approach and laboratory evaluation of renal disease. In: Textbook of Veterinary Internal Medicine (Ettinger SJ \& Feldman EC, editors), $5^{\text {th }}$ edition. WB Saunders, Philadelphia, Pp 1600- 1614. receptors on the kidney tubules and vessels (Menegaz et al., 2000). Talukder \& Hikasa (2009) revealed another possible pathway of alpha-2 adrenoceptor action in causing natriuresis and diuresis when they demonstrated an increased level of atrial natriuretic pepetide (ANP) in the plasma of dogs that received xylazine. When post synaptic alpha-2 adrenoceptors are stimulated, the hypertension that ensured always triggers a reflex mediated AVP release from the cardiac atrium.

These alpha-2 adrenoceptor effects of xylazine could as well explain the natriuresis, diuresis and kalliuresis observed in the dogs of the two treatment groups. Although we could not categorically explain the process of renal handling of ketamine because this study is limited by our inability to evaluate the renal clearance of ketamine simultaneously with that of creatinine and other electrolytes, we can still to some reasonable extent conclude that the effects seen in this study is Xylazine's and that Ketamine even when used at $100 \%$ increase in dose cannot reverse the action of xylazine but may rather potentiate its actions.

DiBona GF \& Kopp UC (1997). Neural control of renal function. Physiological Reviews, 77(1): 75175.

Edwards RM \& Gellai M (1988). Inhibition of vasopressin stimulated cyclic AMP accumulation by alpha-2 adrenoceptor agonists in isolated papillary collecting ducts. Journal of Pharmacology and Experimental Therapeutics, 244(2):526-530.

Gellai M \& Edwards RM (1988). Mechanisms of alpha 2- adrenoceptor agonist- induced dieresis. American Journal of Physiology, 255(2pt2): 317-323.

Green DM \& Farah A (1949). Influence of filtered load on sodium excretion. American Journal of Physiology,154:444- 456.

Haskins SC, Farver TB \& Patz JD (1985): Ketamine in dogs. American Journal of Veterinary Research, 46(9): 1855-1860.

Hirasawa H \& Yanezawa T (1975). The effects of ketamine and innovar on the renal cortical and medullary blood flow of the dog. Anesthetist, 24(8): $349-353$.

Hirota K \& Lambert DG (1996). Ketamine: its mechanism of action(s) and unusual clinical uses. British Journal of Anaesthesia, 77(4):441 - 444 . 
Hughes JML (2008). Anaesthesia for the geriatric dog and cat. Irish Veterinary Journal, 61(6) 380387.

Humphreys MH, Reid IA \& Chou LY (1975). Suppression of antidiuretic hormone by clonidine in the anaesthetized dog. Kidney International, 7(6): 405-412.

Menegaz RG, Kapusta DR \& Cabral AM (2000). Role of intrarenal alpha-2 adrenoceptors in the renal responses to xylazine in rats. American Journal of Physiology, 278(4): R1074-R1081.

Nashat FS, Tappin JW\& Wilcox CS (1976). Plasma sodium concentration and excretion in anaesthetized dog. Journal of Physiology, 254: 183 - 202.

Selkurt EE \& Post RS (1950). Renal clearance of sodium in the dog: Effect of increasing sodium load on reabsorptive mechanism. American Journal of Physiology, 162(3): 639-648.
Smyth DD, Unemura S, Yang E \& Pettinger WA (1987). Inhibition of rennin release by alpha-2 adrenoceptor stimulation in the isolated perfused rat kidney. European Journal of Pharmacology, 140(1): $33-48$.

Talukder H \& Hikasa $Y$ (2009). Diuretic effects of medetomidine compared with xylazine in healthy dogs. Canadian Journal of Veterinary Research, 73(3): 224- 236.

Watson ADJ, Lefebvre HP, Concordet D, Laroute V, Ferre J, Braun J, Conchou F \& Toutain P (2002). Plasma exogenous creatinine clearance test in dogs: Comparison with other methods and proposed limited sampling strategy. Journal of Veterinary Internal Medicine, 16(1): 22- 33.

Wong DHW \& Jenkins LC (1974). An experimental study of the mechanism of action of ketamine on the central nervous system. Canadian Anaesthetist Society Journal, 21(1): 57- 67. 